\title{
PLUG-IN HYBRID ELECTRIC VEHICLES (PHEVS): A POSSIBLE PERVERSE EFFECT GENERATED BY ENVIRONMENTAL POLICIES
}

\author{
PEDRO PABLO RAMÍREZ SÁNCHEZ ${ }^{1}$, ALASSANE BALLÉ NDIAYE ${ }^{1}, \&$ ROBERTO RENDEIRO \\ MARTÍN-CEJAS ${ }^{2}$ \\ ${ }^{1}$ Université Libre de Bruxelles, Belgium. \\ ${ }^{2}$ Universidad de Las Palmas de Gran Canaria, Spain.
}

\begin{abstract}
The automotive industry is one of the largest polluters, affecting air quality in urban areas. For this reason, the effect of the public policies on the sector is very important in economic and social terms. In this sense, one of the policies has been the subsidies for efficient vehicles where the plug-in hybrid electric vehicles (PHEVs) are included. Subsidies are very important for some of these vehicles, with a real price which is not competitive in comparison with internal combustion (IC) cars. As an example, the sales have dropped in Denmark in 2016 after the incentive reduction.

However, in some cases, policies designed to regulate the situation can create some perverse effects due to the complexity of this issue.

This type of vehicle is powered by an IC engine in combination with one or more electric motors using energy stored in battery packs. The real efficiency of this kind of vehicle depends strongly on the responsibility of the owner. Only if the car has been plugged in, their batteries have been fully charged and also the car is driven under "efficient mode", the emissions will reduce significantly.

Considering the fuel consumption gap between manufacturer declaration and real drive test and the emissions in different pollutants of the PHEVs in comparison with IC cars, the aim of this article is to show a new possible perverse effect generated by them. This has happened recently with diesel cars, favoured by policies focused in $\mathrm{CO}_{2}$ emission, generating $\mathrm{NO}_{x}$ high level in the urban area air quality.

Finally, we highlight the main result and conclude emission cost implemented in fuel tax as 'the first best' in environmental policies.
\end{abstract}

Keywords: air quality, $\mathrm{CO}_{2}$, environmental policy, internal combustion vehicles (IC), $\mathrm{NO}$, plug-in hybrid electric vehicles (PHEVs).

\section{INTRODUCTION}

On the one hand, the automotive industry is one of the most important sectors in the European Union (EU), involving different sectors like manufacturing, transport, sales, services, etc. According to the European commission data, the sector provides jobs for 12 million people in Europe and accounts for 4\% of the EU's GDP. The EU is among the world's biggest producers of motor vehicles (23\% of world motor vehicle production in 2017) and the sector represents the largest private investor in research and development (R\&D) [1]. This industry is also a vital source of government revenue. According to ACEA, the fiscal income from motor vehicles in the EU15 is $€ 413$ billion annually, which is almost three times the total budget of the European Union [2].

On the other hand, the road transport is the most important polluter in European urban areas. In 2017, in 23 of the 28 member states the air quality standards were still being exceeded - in total in more than 130 cities across Europe - with $\mathrm{NO}_{2}$ (nitrogen dioxide) and PM10 (particulate matter) being the most problematic pollutants [3].

When we talk about air emissions, most people think only about $\mathrm{CO}_{2}$ emissions and global warming, obviating the real dimension about this subject.

According to the Environmental Protection Agency of the United States (EPA), under the 1990 Amendments to the Clean Air Act, it is necessary to regulate sources emitting major 

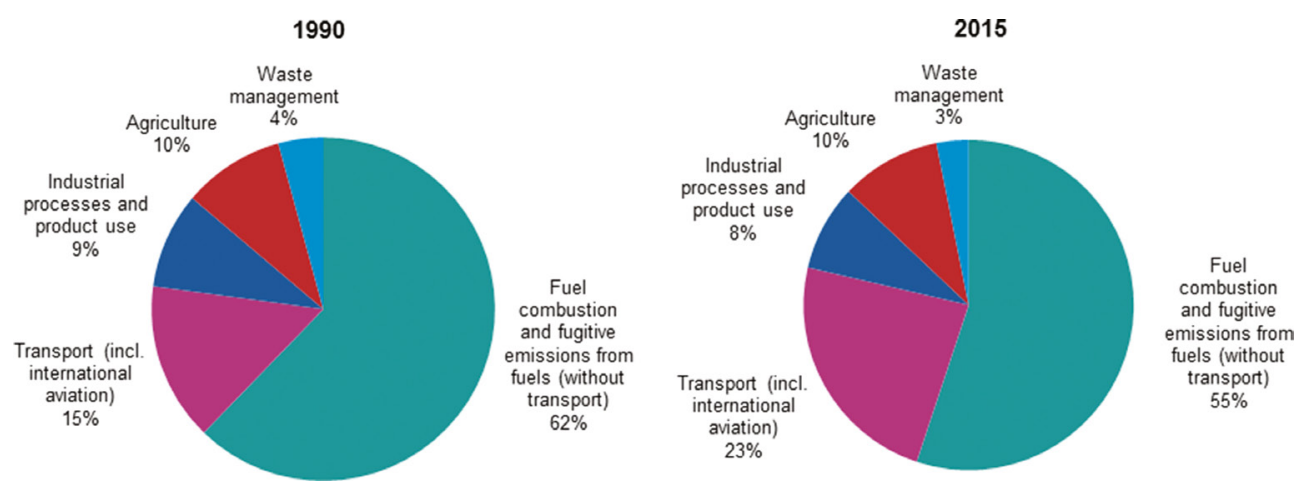

Figure 1: GHGE in 1990 and 2015 in EU-28. (EUROSTAT)

amounts of 188 toxic air pollutants [4]. The importance of this issue lies in the potential human health and environmental effects that exposure to these pollutants under certain conditions cause. At this point, it is important to clarify that contrary to general opinion, $\mathrm{CO}_{2}$ does not cause any damage to health. This gas has an important effect in global warming (it is the principal cause) but has no toxicity at all in its atmospheric concentrations. The pie chart in Fig. 1 shows the greenhouse gas emissions (GHGEs) in 1990 and 2015 in EU-28 expressed like a percentage of total emissions [5].

In this kind of data, it is possible to find some differences in the different sources, mainly due to the considerations in the transport sector. In some statistics, the emissions from international aviation and maritime shipping are not included or are only included from bunker fuels. The transport sector is the unique one that has increased its percentage participation in GHGE (from $15 \%$ in 1990 to $23 \%$ in 2015).

The next bar chart represents the share in percentages of the different transport modes in the total emissions of the main air pollutants in EU in 2016 [6].

In Fig. 2, we can observe immediately that, except for sulphur oxides, road transport is the stronger polluter in the transport sector. In this circumstance, it is especially important,

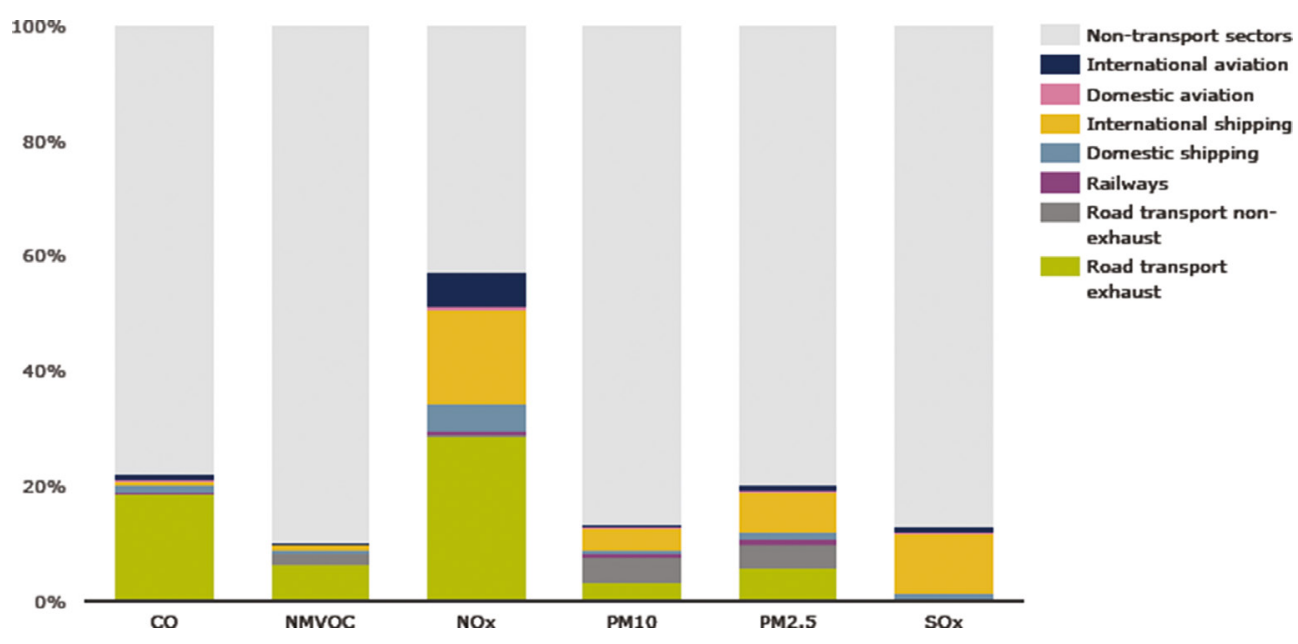

Figure 2: Transport sector in total emissions of the main air pollutants. (EEA) 
considering that a big part of the road transport emissions take place in urban areas. This has a strong impact on air quality and consequently on human health. According to the European Commission, more than 400,000 citizens die prematurely in the EU each year as a result of poor air quality. Millions more suffer from respiratory and cardiovascular diseases caused by air pollution. Persistently high levels of nitrogen dioxide $\left(\mathrm{NO}_{2}\right)$ caused almost 70,000 premature deaths in Europe in 2013. This was almost three times the number of deaths by road traffic accidents in the same year [3].

The aim of this article is to analyse the perverse effect presented by the PHEVs, which has been incremented in EU due to environmental policies.

This article is focused on passenger cars because, on the one hand, "passenger cars" is the most significant category in road transport (near $87 \%$ of this transport sector in EU). The PHEV technology is practically only present in this category. For both reasons this article is focused on passenger cars. Others categories of vehicles with PHEV technology are very rare and they have been launched to show future possibilities. For this reason, there is only data available of the environmental effect of this technology in passenger cars.

The utility of this research lies in this being the first step or basis to improve and optimize actual policies.

\section{VEHICLE FLEET IN EUROPE}

In the European Union, in 2015, there were a total of 289,856,566 vehicles in use representing passenger cars, which is nearly $87 \%$ of the total. The average rate of passenger cars in EU was 494 cars per 1000 inhabitants in 2015. This motorization rate is not homogeneous, varying from 261 in Romania to 661 in Luxembourg [7].

The next pie chart (Fig. 3) shows the passenger car fleet by fuel type in percentage of categories in 2015 in EU [7].

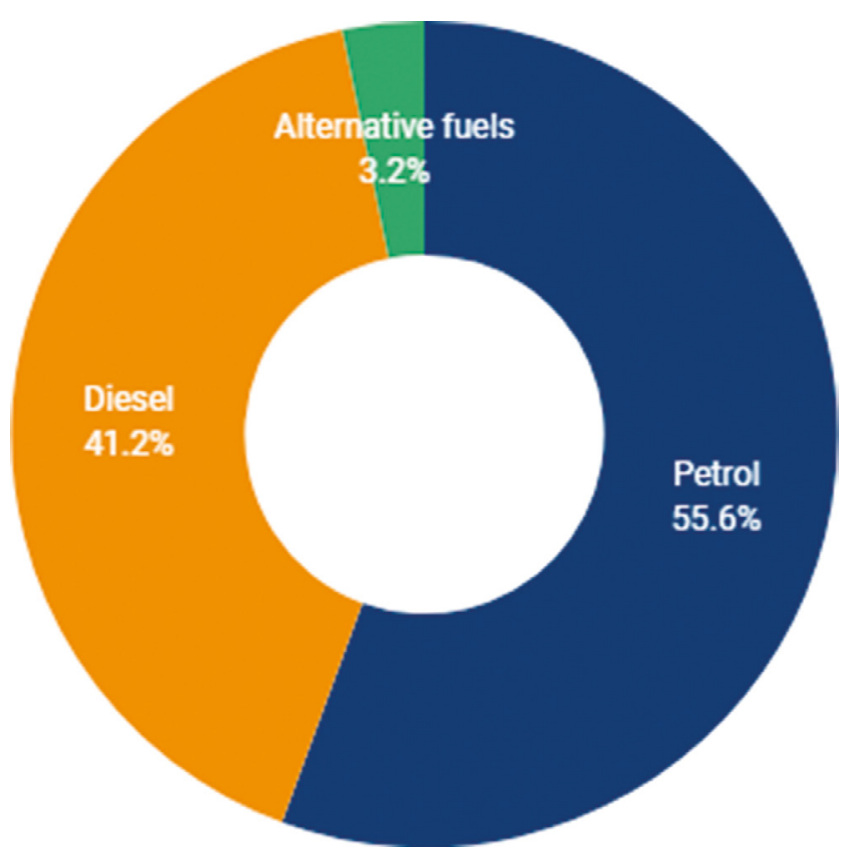

Figure 3: Passenger car fleet by fuel type. EU in 2015. (ACEA) 


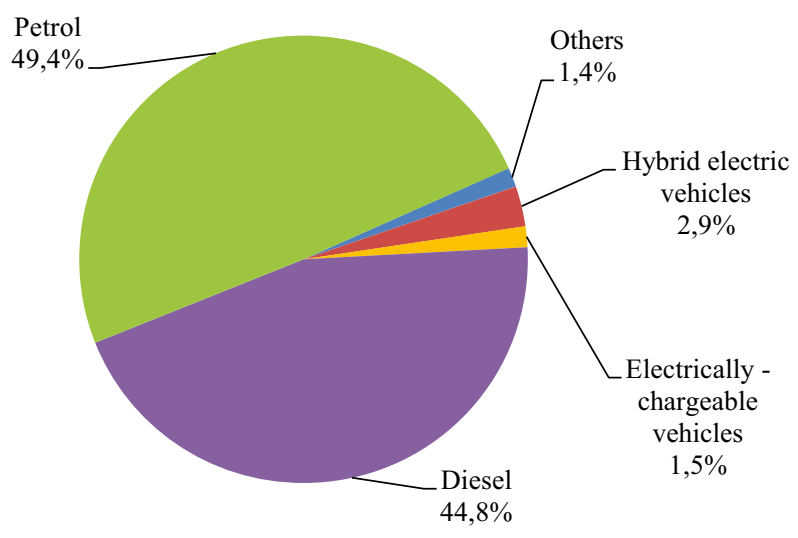

Figure 4: New registration passenger car fleet by fuel type. EU15 in 2017. (ACEA)

It is important to clarify that in Fig.3 under "alternative fuels" category are included electric vehicles (chargeable and hybrid), natural gas vehicles, LPG, etc. Besides, the share in the different categories is not homogeneous in the different countries, and the environmental awareness, economic capacity and the different taxation policies are important factors with strong inference by the consumers. It is important to remark that the repartition in passenger car fleet by fuel type is continually changing. on the one hand; alternative types (electric and hybrids) are constantly growing and on the other hand measures to fight $\mathrm{NO}_{2}$ have decreased new diesel car registrations. For this reason, the actual fleet composition is not necessarily representative of the coming fleet: nearest future fleet. It would be interesting to see the comparison with the new registration fleet composition.

The pie chart (Fig. 4) shows the new passenger cars (new registrations) in the UE15 by fuel type in percentage of categories in 2017 [2].

It is important to consider some remarks in Fig. 4:

In the category 'Electrically chargeable vehicles' are included battery electric vehicles (BEVs), extended-range electric vehicles, plug-in hybrid electric vehicles (PHEVs) and fuel cell electric vehicles (FCEV)

In the category 'Hybrid electric vehicles' are included full and mild hybrids.

In the category 'Others' are included natural gas vehicles (NGVs), LPG-fuelled vehicles and ethanol (E85) vehicles.

\section{PLUG-IN HYBRID ELECTRIC VEHICLES (PHEVS)}

Under the category 'electric vehicle (EVs)' there are different types with important differences.[8]

The PHEVs are powered by an internal combustion (IC) engine in combination with one or more electric motors using energy stored in battery packs. Their batteries are greater than hybrid electric vehicles (HEVs), and to obtain the best efficiency, the batteries must be charged on grid because by their dimension it is not efficient to fill them up by the braking regenerative system. The real efficiency of this kind of vehicle depends strongly on the behaviour of the owner, and only if it has been plugged will it reduce significantly the emissions.

In contrast, when the car is working only with the combustion engine the emission would be greater than IC vehicle, because the battery weight is significant. This is the reason that 
there is a big difference between manufacturers' declared consumption and the real driving consumption.

It is important to highlight that some of these cars have different driving modes (eco, sport). Some constructors have a mode to charge the batteries with the combustion engine (in this case, there is an overconsumption compared with an IC vehicle). This mode has probably been designed to access low emission zones (LEZs), and in practice this means that this vehicle will have a global overemission.

\section{ENVIRONMENTAL POLICIES IN THE EU: PERVERSE EFFECT GENERATED}

Now that we have evidence about the externalities generated by road transport, it is necessary to approach the different tools to internalize the social cost generated. We can consider three types of policy instruments for sustainable transport: physical policies (policies with a physical infrastructure like public transport, new roads, etc.), soft policies (non-tangible measures such as car sharing, tele-working, etc.) and knowledge policies (technological innovations) [8].

In this article, we are going to focus on the policies that according to us present a potential perverse effect in the PHEVs.

\subsection{Vehicle standards:}

It is the definition of acceptable and mandatory limits for safety, exhaust emissions and fuel efficiency of the new vehicles sold. It is important to highlight that standards allow not only for improvements in vehicle motor technology, but that there are also other technological improvements (fuel-efficient tyres and air conditioning, traffic management and ecodriving) and an increased use of biofuels [8].

Although vehicle standards may reduce fuel consumption and consequently $\mathrm{CO}_{2}$ emissions, they will also reduce the cost of driving, creating a stronger incentive to drive. This "rebound effect' of additional driving could be as large as the benefits [9].

In Europe, there are basically two standards, the most significant and known about is the Euro normative (Euro I, Euro II, ....., Euro 6, etc.) that introduces emission limits for diesel and petrol vehicles. This normative regulates emissions of nitrogen oxides $\left(\mathrm{NO}_{\mathrm{x}}\right)$, total hydrocarbon (THC), non-methane hydrocarbons, carbon monoxide (CO) and PM. This policy had started in 1970 with the Directive 70/220/EEC.

The other one is to limit the carbon dioxide, REGULATION (EC) No 443/2009 OF THE EUROPEAN PARLIAMENT AND OF THE COUNCIL of 23 April 2009, setting emission performance standards for new passenger cars as part of the Community's integrated approach to reduce $\mathrm{CO}_{2}$ emissions from light-duty vehicles. At this point, it is important to clarify that this normative puts a limit for the average of the cars manufactured for the company, not in each car separately. The emissions are limited under a standard cycle, so this policy is strongly linked to the test procedure used. Currently, the vehicle standard policy is referred to WLTP (worldwide harmonized light vehicle test procedure) applied from September 2017. Before the WLTP, the standard used was NEDC standard (New European Driving Cycle) designed in the 1980 s.

The driving cycle is crucial for the manufacturers because they are the measurement reference to homologate the cars under the vehicle standard. The dilemma about the utilization of the driving cycle is the gap between them and the real driving conditions. That is the principal reason of the substitution of NEDC by WLTP, nearer to real driving. 
The declared $\mathrm{CO}_{2}$ emissions have been affected by he change in the diving cycle, from NEDC to WLTP. This change has been measured using the ratio WLTP/NEDC. According to this ratio, the category that has been affected the most is HEV with values from 1.23 to 1.37 and that which has been benefitted the most is the PHEV with a ratio value of 1 . Even the BEVs and FCEVs have been affected because the WLTP to NEDC ratio for BEVs and FCEVs refers to the electric energy consumption. The peculiar result for PHEVs is because the ratio WLTP/NEDC strongly depends on the capacity of electric battery, increasing its capacity this type of vehicles will not be affected [10].

An important perverse effect is a growing gap between vehicle standard and real driving conditions. One of the principal objectives of vehicle standard is to encourage the fuel economy and the emissions as a consequence. However, the objective of the authorities does not necessarily coincide with the results obtained, which could imply an inefficiency of this measure.

The average gap across all brands in Europe is quickly growing. The average gap has grown up to $42 \%$ in 2015 from $28 \%$ in 2012 [11].

The carmakers have designed the new cars focused on the driving cycles, these conditions are not necessarily the optimal in real conditions. Like an extreme example of this situation, there is the 'dieselgate scandal' in 2015, where Volkswagen has used devices to defeat the test. The European obligatory rules on carbon emissions required car manufacturers to limit their car fleet to a maximum of $130 \mathrm{~g}$ of $\mathrm{CO}_{2}$ per $\mathrm{km}$ in 2015 , and the situation will become even more complicated with a maximum of $95 \mathrm{~g}$ by 2021. The Commission has proposed more stringent $\mathrm{CO}_{2}$ limits for 2025 in July 2017.

Deceptive fuel consumption figures costs the typical driver in Europe around €549 a year in additional fuel bills compared to the official claims [11].

Another element that has produced a gap and made a difference is the actual cycle test optimal driving mode and the driving mode of each individual consumer. In this sense, it is expected to improve the situation by the development of autonomous driving technologies. The gap between manufacturer and real drive data are not homogeneous in different types of cars. To show the difference between different technologies, we have collected some random models from the ADAC (Allgemeiner Deutscher Automobil-Club) [12]. The data collected are shown in Table 1.

Due to the fact that $\mathrm{CO}_{2}$ emissions are strongly linked to fuel consumption, there is a stoichiometric relationship between each fuel and $\mathrm{CO}_{2}$, and the considerations about the gap consumption are also applicable to $\mathrm{CO}_{2}$ emissions.

There are also similar behaviours in the emission evolution to other pollutants. $\mathrm{CO}_{2}$ is not the unique pollutant regulated under standard vehicle emission, so it is interesting to know how the emissions in different pollutants in each one of the different categories are. Table 2 shows the emissions in different pollutants in some random models in different technologies obtained from ADAC [12].

It is really interesting to pay attention to the gap in the different vehicle types; we can see how the PHEVs present the strongest gap with an important difference. The efficiency of this kind of car is linked to the user behaviour, presenting the best efficiency when the batteries have been charged on grid and it is under this condition that the driving tests are normally done. So depending on the user, the gap in this category can be increased more.

We have commented on how the PHEVs are not affected by the change from the NEDC cycle to WLTP, because the WLTP/NEDC $\mathrm{CO}_{2}$ emission ratio strongly depends on the capacity of the electric battery. The manufacturer has increased the capacity of them for this reason. 
Table 1: Fuel consumption gap: manufacturers' declaration vs. real drive test (ADAC. Allgemeiner Deutscher Automobil-Club).

\begin{tabular}{|c|c|c|c|c|c|}
\hline Model car & $\begin{array}{l}\text { Type of } \\
\text { car }\end{array}$ & $\begin{array}{l}\text { Power } \\
(\mathrm{kW})\end{array}$ & $\begin{array}{l}\text { Manufactur- } \\
\text { er consump- } \\
\text { tion L/100 } \\
\mathrm{km}\end{array}$ & $\begin{array}{l}\text { ADAC } \\
\text { consumption } \\
\text { L/100 km }\end{array}$ & $\begin{array}{l}\text { Gap } \\
\text { consumption \% }\end{array}$ \\
\hline $\begin{array}{l}\text { Audi A3 Sportback } 1.5 \\
\text { TFSI cod sport S tronic } \\
\text { (7-Gang) }\end{array}$ & Gasoline & 110 & 5 & 6.4 & $28.00 \%$ \\
\hline $\begin{array}{l}\text { Alfa Romeo Giulietta } \\
1.4 \mathrm{~TB} 16 \mathrm{~V}\end{array}$ & Gasoline & 88 & 6.2 & 7.5 & $20.97 \%$ \\
\hline $\begin{array}{l}\text { Mercedes GLA } 220 \\
\text { Style 4MATIC 7G-DCT }\end{array}$ & Gasoline & 135 & 6.5 & 7.5 & $15.38 \%$ \\
\hline $\begin{array}{l}\text { Citroen C4 BlueHDi } \\
150 \text { Stop\&Start Shine }\end{array}$ & Diesel & 110 & 4.1 & 4.9 & $19.51 \%$ \\
\hline $\begin{array}{l}\text { BMW X1 sDrive } 18 d \\
\text { xLine Steptronic }\end{array}$ & Diesel & 110 & 4.5 & 5.4 & $20.00 \%$ \\
\hline $\begin{array}{l}\text { Peugeot } 308 \text { SW } 2.0 \\
\text { BlueHDi } 180 \text { GT EAT8 }\end{array}$ & Diesel & 130 & 4.6 & 5.9 & $28.26 \%$ \\
\hline $\begin{array}{l}\text { VW Passat Variant } 2.0 \\
\text { TDI }\end{array}$ & Diesel & 140 & 4.3 & 5.2 & $20.93 \%$ \\
\hline $\begin{array}{l}\text { VW Passat Variant GTE } \\
\text { DSG }\end{array}$ & PHEVs & 160 & 1.7 & 3.8 & $123.53 \%$ \\
\hline $\begin{array}{l}\text { Porsche Panamera } 4 \\
\text { E-Hybrid PDK }\end{array}$ & PHEVs & 340 & 2.5 & 5.3 & $112.00 \%$ \\
\hline $\begin{array}{l}\text { BMW 225xe iPer- } \\
\text { formance Active Tourer } \\
\text { M Sport Steptronic }\end{array}$ & PHEVs & 165 & 2 & 6.3 & $215.00 \%$ \\
\hline $\begin{array}{l}\text { Hyundai IONIQ PlugIn- } \\
\text { Hybrid Premium }\end{array}$ & PHEVs & 104 & 1.1 & 2.5 & $127.27 \%$ \\
\hline $\begin{array}{l}\text { Toyota Prius } 1.8 \text { Hybrid } \\
\text { Executive }\end{array}$ & HEVs & 90 & 3.3 & 4.1 & $24.24 \%$ \\
\hline $\begin{array}{l}\text { Lexus CT 200h } \\
\text { Executive Automatic }\end{array}$ & HEVs & 100 & 3.8 & 5.4 & $42.11 \%$ \\
\hline $\begin{array}{l}\text { Hyundai IONIQ Hybrid } \\
\text { Premium }\end{array}$ & HEVs & 104 & 3.9 & 5.1 & $30.77 \%$ \\
\hline
\end{tabular}

It is interesting to consider that batteries with bigger capacity can increase the efficiency under an environmental responsible user. In contrast, the inefficiency can be increased by an irresponsible user (bigger batteries means a heavier car).

So, for these reasons, the spread of the PHEVs could be considered as a perverse effect under certain circumstances. 
In Table 2, we can observe how the diesel car presents the biggest emission in $\mathrm{NO}_{\mathrm{x}}$ (this is the reason new EU policies are focused in the regulation of this technology); nevertheless diesel cars present the best results in PM and HC (hydrocarbon) results. To analyse the particulate emission data is interesting, considering the total emission $(\mathrm{mg} / \mathrm{km})$ and the number of particles. The size of the particles is directly linked to their potential for causing health problems. Small particles less than $10 \mu \mathrm{m}$ in diameter pose the greatest problems, because they can get deep into your lungs, and some may even get into your bloodstream [13]. For this reason, it is interesting to compare the column of PM emission $(\mathrm{mg} / \mathrm{km})$ with the last column (number of particles per $\mathrm{km}$ ). A greater number of particles indicate an emission of smaller particles.

Analysing the PM data, we can observe how the diesel car presents the best result and on the other side are the PHEVs with an enormous difference. PHEVs present worse results than gasoline cars in $\mathrm{NO}_{x}$, and as we have commented in previous sections, it is important to considerer that PHEV data is more optimistic than diesel and gasoline cars. In the real emission test, the emission of this type of car is strongly linked to the mode driving selected and the user behaviour if the batteries have been charged.

So, the spread of the PHEVs could be considered as a perverse effect under PM emission perspective. If the PHEVs are going to substitute a significant part of gasoline cars, looking at $\mathrm{NO}_{\mathrm{x}}$ emission data, it is also possible that with this pollutant we are going to have another perverse effect.

\subsection{Taxes on purchase and ownership of a vehicle}

In the EU there are different policies applied in each country, even some countries apply different policies in their different regions.

In relation taxes on acquisition and ownership, the most common element considered is the $\mathrm{CO}_{2}$ emissions; this circumstance has benefited diesel cars and is an explicative factor about the strong presence of diesel in the European fleet.

Actually, in the 'diesel recession', the taxes focused on $\mathrm{CO}_{2}$ emissions to encourage the PHVs due to their theoretical consumption in a standard cycle. This could be considered as a perverse effect.

\subsection{Subsidies to efficient vehicles}

The designing of subsidies needs to be carefully matched to technological information and information about the specific local characteristics; care must be taken not to inadvertently create perverse incentives [8].

Subsidies are very important for EVs, with a real price not competitive in comparison with IC cars. As an example, sales dropped in Denmark in 2016 after incentive reduction [15].

In section 3 we have shown how the PHEVs in some cases can be very pollutant, specially when the IC engine is used to charge the batteries. An example of the perverse effect generated has been recently published by the BBC, displaying the situation in the UK, where government subsidized plug-in cars may never have been charged [16]. Possibly, the situation in other countries will be similar. 


\subsection{Low emission zone}

The objective of this policy is improving the air quality in urban areas controlling the access where only some vehicles are permitted. This policy encourages the commercialization of some types of cars like EVs, so if the regulators do not have a deep knowledge about the pros and cons of them, this can produce some perverse effects.

In the case of PHEVs, one of the modes used is to charge the batteries with the IC engine. This mode has been designed just to access the LEZ and presents a strong perverse effect in peripheral zones, where the car presents an overconsumption (This implies an over emission). This situation would present some controversy if overemission happens in an economic depressed zone just to access richer areas. Furthermore, it is important to take into account the transboundary nature of pollution, even more if we consider the secondary pollutants.

\section{CONCLUSION}

The principal aim in European transport policies has been the $\mathrm{CO}_{2}$ mitigation. As a result, diesel cars have seen an enormous growth in some countries, and now the principal problem in air quality of urban areas is the $\mathrm{NO}_{\mathrm{x}}$ from diesel cars. Now the principal aim is the $\mathrm{NO}_{\mathrm{x}}$ reduction, but the policies implemented are encouraging vehicles with inefficient modes promoting relocation of emissions like the PHEVs. In this article, we have shown that PHEVs present the strongest gap consumption (with scandalous differences above 100\%). This situation has been reinforced with the change from NEDC to WLTP because the PHEV not has been affected. The situation is similar with $\mathrm{HC}$ and PM emissions, like we have shown in the data tables. This will probably mean that there will be increasing levels in $\mathrm{CO}_{2}, \mathrm{HC}$ and PM in coming years if the PHEVs are growing. In addition, the PHEVs present other possible perverse effects, like charging batteries by IC engine. In this case, the emissions from PHEVs would be even greater than the data shown in this article. We can summarize that the actual policy is generating a 'pendulum shift effect'.

Because a good combination and integration of policies can lead to positive effects and synergies. It would be important to consider that cars pass the emission test always using the most inefficient 'driving mode' offered by the manufacturer (to encourage them to offer only efficient driving modes), avoiding as much as possible the perverse effects. Also, It would also be necessary to consider emissions as a whole and not focus pollutants separately, according to EU legislation on ambient air quality and cleaner air for Europe (Directive 2008/50/EC) this sets air quality limits that cannot be exceeded anywhere in the EU, and obliges Member States to limit the exposure of citizens to harmful air pollutants. The need both to lessen the use of natural non-renewable resources and to slow down the global warming implies radically different economic planning to the current pattern [17]. In this sense, it is necessary to highlight that emission taxes are the first best instrument to correct emission externalities and induce the optimal driving behaviour and vehicle's purchase and usage choice [18].

To develop a methodology to associate emission taxes to emission packages would be simple with carbon dioxide emission, because there is a stoichiometric ratio between each fuel and $\mathrm{CO}_{2}$ emission and a market price for this pollutant. It is not the same for the other pollutants. The development of a methodology for them is extremely complicated and needs a deep knowledge about this issue. We can assume that is not possible to monitor pollution generated by each vehicle separately, but nevertheless, we can calculate the average of the sector using methodologies to estimate total emissions by emission factors and activity data 
like COPERT (COmputer Programme to calculate Emissions from Road Transport). After that, it is simple to obtain the average emission in the different pollutants per fuel litre consumption. We can assume this average like the 'second-best' (term used in economics to describe something that you have to accept even though you would have preferred something else) to calculate emissions per user [19].

Subsequently, after estimating the emissions, it would be necessary to estimate the "shadow price' (monetary value assigned to currently unknowable or difficult-to-calculate costs) of the emissions. There are several studies on average and marginal air pollution costs [20]. ExternE project and CAFE CBA (Clean Air For Europe Cost-benefit analysis) developed in Europe are examples of this. Probably, it would be necessary to confront different studies and harmonize a global methodology.

\section{REFERENCES}

[1] Automotive industry I Internal Market, Industry, Entrepreneurship and SMEs [Internet], available at https://ec.europa.eu/growth/sectors/automotive_en, [accessed 6 March 2019]

[2] ACEA_Pocket_Guide_2018-2019.pdf [Internet], available at https://www.acea.be/uploads/publications/ACEA_Pocket_Guide_2018-2019.pdf, [accessed 6 March 2019]

[3] European Commission - PRESS RELEASES - Press release - Commission warns Germany, France, Spain, Italy and the United Kingdom of continued air pollution breaches [Internet], available at http://europa.eu/rapid/press-release_IP-17-238_en.htm, [accessed 27 February 2019]

[4] Air Toxics Emissions: EPA's Strategy for Reducing Health Risks in Urban Areas. 4.

[5] File:Greenhouse gas emissions, analysis by source sector, EU-28, 1990 and 2015 (percentage of total) new.png - Statistics Explained [Internet], available at https://ec.europa. eu/eurostat/statistics-explained/index.php?title=File:Greenhouse_gas_emissions, analysis_by_source_sector,_EU-28,_1990_and_2015_(percentage_of_total)_new.png, [accessed 27 February 2019]

[6] Emissions of air pollutants from transport - European Environment Agency [Internet], available at https://www.eea.europa.eu/data-and-maps/indicators/transport-emissionsof-air-pollutants-8/transport-emissions-of-air-pollutants-6, [accessed 27 February 2019]

[7] ACEA_Report_Vehicles_in_use-Europe_2017.pdf [Internet], available at https://www. acea.be/uploads/statistic_documents/ACEA_Report_Vehicles_in_use-Europe_2017. pdf, [accessed 7 March 2019]

[8] Difference Between Hybrid, Mild Hybrid, BEV and PHEV [Internet], available at https://www.autotrader.ca/newsfeatures/20180410/types-of-electric-vehicles-explained/, [accessed 10 April 2019].

[9] Santos, G., Behrendt, H., \& Teytelboym, A., Part II: Policy instruments for sustainable road transport. Research in Transportation Economics, 28(1), pp. 46-91, 2010 Jan.

[10] Portney, P.R., Parry, I.W., Gruenspecht, H.K., \& Harrington W., Policy watch: The economics of fuel economy standards. Journal of Economic Perspectives, 17(4), pp. 203-17, 2003 Nov.

[11] Tsiakmakis, S., Fontaras, G., Cubito, C., Pavlovic, J., Anagnostopoulos, K., \& Ciuffo, B., From NEDC to WLTP: effect on the type-approval $\mathrm{CO}_{2}$ emissions of light-duty vehicles. 50. 
[12] Mercedes, the greatest deception in Europe's car fuel economy history - report I Transport \& Environment [Internet], available at https://www.transportenvironment.org/ press/mercedes-greatest-deception-europe $\%$ E2\%80\%99s-car-fuel-economy-historyreport, [accessed 27 February 2019]

[13] ADAC EcoTest - Fünf Sterne für die Umwelt [Internet], available at https://www.adac. de/infotestrat/tests/eco-test/default.aspx, [accessed 19 February 2019]

[14] Health and Environmental Effects of Particulate Matter (PM) I Particulate Matter (PM) Pollution I US EPA [Internet], available at https://www.epa.gov/pm-pollution/healthand-environmental-effects-particulate-matter-pm, [accessed 27 February 2019]

[15] Global EV Outlook 2017. pp. 71, 2017.

[16] Government-subsidised plug-in cars may never have been charged - BBC News [Internet], available at https://www.bbc.com/news/business-46152853, [accessed 27 February 2019]

[17] Rendeiro Martín-Cejas, R., \& Pablo Ramírez Sánchez, P., Ecological footprint analysis of road transport related to tourism activity: The case for Lanzarote Island. Tour management, 31(1), pp. 98-103, 2010 Feb.

[18] Acutt, MZ., \& Dodgson, JS., Controlling the environmental impacts of transport: Matching instruments to objectives. Transportation Research Part D: Transport and Environment, 2(1), pp. 17-33, 1997 Mar.

[19] Cremer, H. \& Gahvari, F., Second-best taxation of emissions and polluting goods. 80, 169 p, 2001.

[20] Verbeek, M., Internalisation Measures and Policies for All external Cost of Transport (IMPACT). :336. 